\title{
The omnipresent hubbub
}

\author{
The Unwanted Sound of Everything We \\ Want: A Book About Noise \\ by Garret Keizer \\ PublicAffairs: 2010.400 pp. $\$ 27.95$
}

In The Unwanted Sound of Everything We Want, writer Garret Keizer exposes the history of noise, its opponents and apologists, and recent efforts to measure and curb it. The result is a scattered mosaic that uses the conceit of human clamour to reveal the paradoxes of post-industrial life.

Engineers use the term 'noise' to refer to anything that interferes with the transmission of a signal. A more familiar kind of noise, arising from machines and people, is omnipresent. It is hard to define, but we know it when we hear it. In 1931 the British physicist G. W. C. Kaye proposed that noise is "sound out of place"; others describe it as unwanted sound, sonic pollution or even sonic abuse.

Although we find misplaced sounds annoying, they were useful signs of danger to our ancestors. Native Americans would avoid camping near running water that could mask the rustle of predators and enemies. For many years, nature was noisier than us: the eruption of the Krakatoa volcano in 1883 is the main contender for the loudest sound ever documented. But recent centuries have seen a steep rise in man-made decibel levels. As Keizer observes, our noisy era owes as much to the invention of the combustion engine and the loudspeaker as it does to Edison's incandescent light bulb, which extended work into hours reserved for prayer, sex and sleep.

Noise has repercussions for public health. Among its problems is the spread of tinnitus, the perception of non-existent sounds, which affects the inner ears of some 50 million Americans, including 70,000 soldiers returning from war. Keizer cites studies linking long-term noise exposure to heart disease in Europe and low birth weight in Japan, with sleep deprivation and stress hormones among the presumed culprits. He suggests that exposure to low frequencies may cause 'vibroacoustic disease', with symptoms such as chest pain. He even proposes that noise pollution is a "hidden cause of sprawl" and contributes to climate change as people move to the suburbs in search of peace and quiet.

As his case builds to a crescendo, Keizer claims that noise is the sound of "our mechanized civilization ... at war with our bodies", seeing it as the inevitable product of "the carbon-based economy, the growth-obsessed economy, the corporate-dominated transportation intensive economy". He closes with an admonition to live more quietly, nudging us to buy less and local, and to burn less carbon.

A handful of governments, Keizer reveals, are attempting to decrease noise. Authorities in the Netherlands that are seeking to justify expensive noise-reduction measures have estimated that millions of euros are lost to sleep deprivation every year. Towns in the Netherlands and New York state have taken

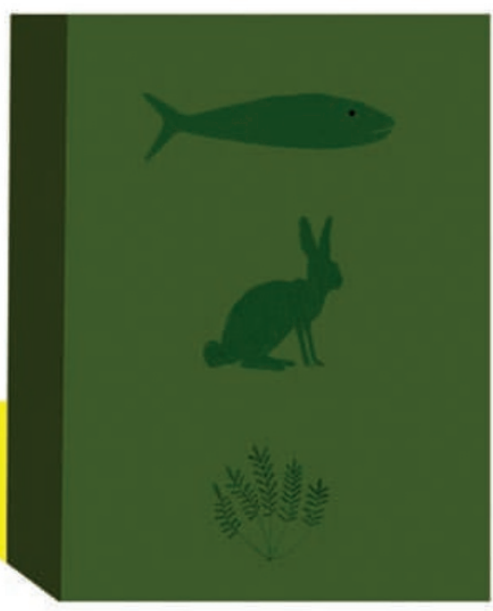

jacket. In perhaps the most creative response, Japan has opted to preserve the crackle of drift ice and the flutter of crane wings on an official list of acoustic landmarks (see go.nature. com/4886KP). But the greatest social impact will come from sweeping laws such as the European Union's directive requiring the production of 'strategic noise maps' of airports and cities from Brussels to Helsinki (see go.nature.com/a4s1SP).

Keizer is an energetic researcher and an omnivorous writer. One could have hoped for more on the physics of sound, the biology of hearing and the craft of acoustical engineering. However, he commendably keeps an open mind about the value of noise, citing the $B B C$ 's recent decision to install a noise-generating machine after employees complained that their new building was too quiet. Ultimately, Keizer comes across not as a dour partisan for silence but as someone who sees the right to quiet as one of many competing rights. It is a virtue of his

wind-farm developers to court for installing turbines that sound, in the words of one resident, like "a cement-mixer in the sky", and Manhattan's recent noise clampdown requires pneumatic drills to have a sound-insulating ruminative study that it conveys the charm of a hushed library and the appeal of the ruckus outside.

Jascha Hoffman is a writer based in San Francisco, California.

e-mail: jascha@jaschahoffman.com

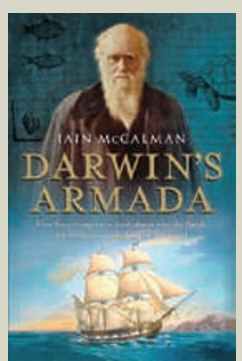

Darwin's Armada: Four Voyagers to the Southern Oceans and Their Battle for the Theory of Evolution by lain McCalman (Pocket Books, $€ 9.99$ ) lain McCalman explores how similar seafaring episodes on scientific voyages linked Charles Darwin and fellow naturalists Joseph Hooker, Thomas Henry Huxley and Alfred Russel Wallace. "McCalman forces us to notice the similarities of the men's intellectual and emotional experiences as well as of their physical privations," wrote Alistair Sponsel (Nature 462, 286-287; 2009).

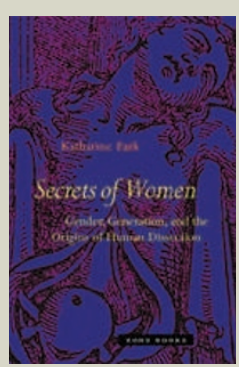

Secrets of Women: Gender, Generation, and the Origins of Human Dissection by Katharine Park (Zone Books, \$22.95) Focusing on female dissections in medieval Italy, the author examines how attempts to discover proof of sainthood or cause of death had a key role in the history of anatomy and revealed the 'secrets' of reproduction and pregnancy. Rina Knoeff wrote: "A 'must read' for anyone working on the history of pre-modern medicine." (Nature 446, 265; 2007.) 